\title{
Crítica de la razón eurocéntrica a través del concepto de naturaleza en Marx: sacralización de la tierra y el cuerpo*
}

Fecha de entrega: 5 de noviembre de 2018

Fecha de evaluación: 14 de diciembre de 2018

Fecha de aprobación: 31 de enero de 2019

\author{
Rogelio Acevedo Oquendo**
}

\section{Resumen}

La tradicional lectura que se hace de Marx como continuador de Hegel, pero ateo y determinista económico o histórico, falsea el propio pensamiento del pensador alemán. Alfred Schmidt y Enrique Dussel, entre otros, muestran en qué medida se trata de un Marx desconocido aún en los medios académicos. Este desconocimiento reviste una inevitable banalización de su legado, lo que dificulta el ejercicio pedagógicopolítico que pueda inspirar el avance social en América Latina. Aclarar en qué fallan estas miradas nos permite encontrar críticas a la razón eurocéntrica, aun cuando el propio Marx fuese eurocéntrico. Tal lectura se hace posible redefiniendo estos aspectos usualmente asociados al marxismo y buscando en qué medida resulta poseurocéntrica. Se trata

* Este texto es producto de las investigaciones realizadas por el autor en torno a la política y la pedagogía como medio para el desarrollo social en América Latina. De esta manera, se acude a Marx para alejarlo del típico discurso en el que se ha enmarcado y se busca darle un nuevo sentido a su pensamiento. Citar como Acevedo Oquendo, R. (2019). Crítica de la razón eurocéntrica a través del concepto de naturaleza en Marx: sacralización de la tierra y el cuerpo. Cuadernos de Filosofía Latinoamericana, 40(120), 139-169. DOI: 10.15332/25005375/5382

* Magister en Filosofía Latinoamericana de la Universidad Santo Tomás y filósofo de la Universidad Nacional. Docente de la Universidad Incca de Colombia y de la Universidad La Gran Colombia. Correo electrónico: rogelioacevedoo@gmail.com 
de poner en cuestión las concepciones de historia, ciencia y naturaleza, alrededor de la antropología materialista — no ontológica- presente en la obra de Marx.

Nos proponemos reflexionar sobre esas cuatro líneas problemáticas en torno a Hegel y Marx - el ateísmo, el determinismo económico e histórico, la idea de historia y la relación entre ciencia y naturalezaque se construyen a la luz de la filosofía materialista marxiana. A partir de las relaciones puestas en juego allí sería posible establecer las bases de una comprensión de la naturaleza - la tierra y el cuerpo- más allá del sesgo de la razón instrumental, ecocida, inmoral y desacralizadora. Una concepción que podría entrar en diálogo con las cosmovisiones indígenas del planeta.

Palabras clave: materialismo, ética, lógica formal, eurocentrismo, lógica dialéctica, lenguaje, monismo teológico.

\section{Critique of Eurocentric reason through the concept of nature in Marx: sacralization of the earth and the body}

\section{Abstract}

The traditional reading of Marx as a continuation of Hegel, but atheist and economic or historical determinist, falsifies the German thinker's own thinking. Alfred Schmidt and Enrique Dussel, among others, show to what extent this is an unknown Marx even in the academic circles. This ignorance is an inevitable banalization of his legacy, which hinders the pedagogical-political exercise that can inspire social progress in Latin America. Clarifying in what do these views fail allows us to find critique of Eurocentric reason, even if Marx himself was Eurocentric. Such reading is made possible by redefining these aspects usually associated with Marxism and looking to what extent it is Post-Eurocentric. It is about questioning the conceptions of history, science and nature, around the materialistic anthropology — not ontological — present in Marx's work. 
We propose to reflect on these four problematic lines around Hegel and Marx - atheism, economic and historical determinism, the idea of history and the relationship between science and naturethat are constructed in the light of Marxist materialist philosophy. From the relationships put into action there it would be possible to establish the basis of an understanding of nature - the earth and the body - beyond the bias of instrumental, ecocide, immoral and desacralizing reason. A conception that could enter into dialogue with the indigenous worldviews of the planet.

Keywords: Materialism, ethics, formal logic, Eurocentrism, dialectical logic, language, theological monism.

\section{Herencia y distancia entre Hegel y Marx. Lógica dialéctica y superación del historicismo}

La vasta obra hegeliana se articula alrededor de la tradición judeocristiana, la Ilustración y, sobre todo, la lógica dialéctica. La ética y la política encuentran su sentido pleno en la dialectización de la ciencia, lo que significa la superación de la escisión entre eticidad y epistemología, en boga por pensadores como Maquiavelo o Hobbes. La acepción de ciencia en Hegel, que supera el restringido universo formalista heredado de Descartes y continuado por los positivistas — desde Hume hasta Karl Popper o Mario Bunge-, resulta significativa para Marx y su vigencia en el siglo xxI. Consideramos que uno de los aspectos clave para la crítica a la ciencia formalista, abstracta y autorreferencial, es la recuperación y actualización de la lógica dialéctica. Esta no solo es opuesta a aquella, sino que integra muchos fenómenos que no logran ser pensados por dicho paradigma científico, como la erótica, el arte o la religión.

El proceder dialéctico no comprende el proceso de pensamiento como actividad intelectiva, sino como praxis social. Esto, por lo menos en Marx, se debe a que no existe en su formación cultural una escisión entre alma y cuerpo, como sí la encontramos en los filósofos cristianos. Diferencia relevante en lo tocante a la epistemología porque los científicos responden a una matriz mitológica de la cual no se pueden separar sino de dos maneras: por medio de la imaginación o porque descubren las contradicciones 
de su cultura con las formas en que se vive. La mente humana se debe a redes simbólicas, en el sentido de la antropología de Roger Bartra1, de las cuales toma elementos para construir teorías sobre la realidad. La matriz simbólica de la cual hace parte Marx es la cultura semita, y de allí tomará su riqueza. Entendemos esa matriz simbólica como lo religioso y su formalización como teología. Por extensión, a la condición simbólica material la podemos entender como episteme y a su formalización como epistemología. En palabras de Marx, se pudiera comprender como el paso de la crítica de la teología a la crítica del Estado y la economía. Pues bien, Marx es culturalmente judío y esta tradición se verá reflejada en su obra.

Ahora bien, la ciencia formalista, por supuesto, también debe sus logros a la estructura material-simbólica de la sociedad donde surge. Solo mediante una abstracción indebida, fetichizada, pueden los cientificistas pensar que sus teorías responden a la realidad en sí misma y no a mitos arraigados no criticados. La tesis isomórfica, improbable identificación de racionalidad con realidad en sí misma, constituye el mito fundante de la lógica formalista. La distancia de Hegel y Marx con la acrítica ciencia es que no sostienen tal tesis. Al contrario, ambos consideran que la realidad es siempre "para sí" - tomando con ello el legado kantiano - o realidad humanizada. También se distancia Marx en que para él no existe una división ontológica entre pensar y hacer, entre las condiciones biológicas y las socioeconómicas. La inclusión de la praxis como condición de posibilidad de la razón deja a la ciencia formalista-positivista en el sitio que le corresponde: el de una ideología funcional a un mundo social que históricamente ha sido inmoral. Muchos de los presupuestos de la ciencia formalista hacen parte de la tradición judeocristiana.

La lógica dialéctica materialista se fundamenta en elementos culturales específicos - hemos de decir, religiosos-, pero susceptibles de modificación en su nivel formal -epistemológico-, lo que hace de este método una herramienta para la praxis humana y no un discurso legitimador. Para comprender de qué manera este método es científico deben considerarse aspectos como el criterio de demarcación científica o los análisis lingüísticos. Creemos que una leve mirada a los presupuestos de la concepción formalista de la ciencia nos permite situar a Marx como crítico de esta, aspecto

1 Antropología del cerebro (Bartra, 2014) ofrece una interesante teoria de la mente y el cerebro de corte materialista, cuya tesis central consiste en que la mente no puede existir fuera de redes simbólicas exocerebrales. Esta tesis emplea lógica dialéctica. Las redes simbólicas son productos culturales construidos socialmente, que proporcionan las condiciones de posibilidad de lo mental. 
generalmente olvidado precisamente por la seducción de la exactitud de las ciencias "duras" - puesta en duda por sus propios adeptos-.

\section{El pensamiento dialéctico como crítica al logos formalista}

Los formalistas parten del supuesto de una relación isomórfica entre el lenguaje y la realidad, generalmente identificando a aquel con la racionalidad. Tales supuestos implican la exclusión epistemológica de formas de pensamiento no ajustadas a la gramática considerada "correcta", como los relatos simbólicos, míticos o religiosos. En su lugar, el lenguaje correcto se concibe como aquel que cumple con el criterio "universal" de la matematización. El convencimiento sobre el carácter "universal" hace olvidar las raíces históricas de estos supuestos. Es decir, bajo la idea de que solamente es posible un lenguaje que represente la realidad tal como es, las condiciones históricas son abstraídas puesto que se supone que tal lenguaje, por coincidir con la realidad en sí misma, no está condicionado por ninguna cosmovisión particular.

Esta actitud redunda en lo que en lógica se conoce como petición de principio. En efecto, si se cree que lenguaje y realidad comparten la misma estructura, se concluye que el lenguaje y la realidad tiene la misma estructura. O dicho de manera más clara, como no es posible probar que efectivamente la realidad en sí misma y un lenguaje ordenado coinciden, entonces se da como un hecho, y acto seguido se procede a demostrar cómo es la realidad en sí misma, esto es, más allá de las perspectivas culturales. No obstante, el supuesto mismo es producto de una construcción cultural - un orden simbólico generalmente mitológico- porque no puede demostrarse, desde el propio criterio formalista, que la realidad en sí y el lenguaje ordenado coinciden pues tendríamos que situarnos fuera del lenguaje mismo para ver esa relación — cosa imposible-.

Así, el presupuesto de dicha coincidencia se debe a la aceptación de una idea no demostrada. De manera que estamos ante una falacia argumentativa dado que lo supuesto es indemostrable y si es indemostrable, según el propio credo formalista, o carece de validez o es evidente. Mas es claro que esta idea no es evidente, de lo contrario no sería necesaria una formalización del lenguaje. El propio criterio formalista no descubriría la prueba de su inconsistencia hasta la aparición de la obra de Gödel. Tal prueba se 
efectuaría, sin embargo, matemáticamente, desde "afuera" de la estructura formal, dada su naturaleza autorreferencial ${ }^{2}$.

Un siglo antes Hegel efectúa una refutación del modelo matemático de su tiempo desde "afuera", conformando una crítica metamatemática pero totalmente distinta a la gödeliana. Esta crítica suele pasar desapercibida en el debate científico, apenas rescatada por autores como Paul Feyerabend. Siguiendo a Kant en su análisis fenomenológico, Hegel establece las condiciones de posibilidad y los límites del modelo matemático autorreferencial, no a partir de la matematización, sino de la idea del devenir ser otro que sí mismo. El movimiento dialéctico se mantiene en el orden del concepto, pero reclamando su "verdad" de lo otro distinto del concepto. La negatividad en Hegel se limita al no ser todavía en el espíritu. Mas sus discípulos disidentes comenzarán una crítica a partir de la no-filosofía. Esta vía es asumida con mayor claridad por Marx, que supera con ello a uno de los críticos más importantes de Hegel, Feuerbach.

El tema de la lógica es bastante complejo y no pretendemos agotar su riqueza en estas páginas. Por el momento es suficiente con indicar las características problemáticas que conformarían para nosotros el centro débil de la lógica formalista. Para empezar, el término formalista no equivale a lógica formal. Por el primero entendemos una extensión del principio formal a toda posibilidad de pensamiento, mientras que por la segunda entendemos un "momento" necesario, pero no suficiente en el proceso de pensamiento. Valga esta aclaración para evitar caer en el error de pensar que la crítica al modelo formalista implica no acatar ningún tipo de formalización. De lo que se trata es de denunciar el sesgo de la formalización que, lejos de ser exacto o preciso, es una reducción del proceso científico.

Por su parte, la fetichización del mercado, también presente en los procesos de pensamiento, es producto de la ideología capitalista, cuyo comienzo no se encuentra en la obra cartesiana, sino en un hecho histórico sin precedentes: la conquista y posterior anexión material e ideológica de la actual América Latina. En el lento periplo de legitimación de la colonización se fue forjando una filosofía abstracta que omitía el genocidio indígena, la esclavitud, la miseria de los trabajadores y, desde mucho tiempo antes, la materialidad, el cuerpo y la mujer. Esta fetichización, presente en la lógica formalista, la describe Lefebvre en los siguientes términos:

2 Tarea emprendida por Hilbert en su trabajo metamatemático. Gödel sería el continuador de dicho proyecto demostrando la incompletitud de cualquier modelo axiomático-demostrativo. 
Los hombres modernos y los economistas toman hacia el oro la misma actitud que un primitivo hacia un fetiche. Le atribuyen un poder independiente de ellos, y ese fetiche, que no es sino obra suya, reina, en efecto, sobre ellos y adquiere este poder. En otros términos, en todo sector no dominado, por ejemplo, en la economía, la actitud "teológica" o "metafísica" subsiste; en particular en el sector social en el que el hombre no domina aún sus propias obras. (2006, p. 83)

Veamos cómo funciona el modelo formalista para comprender en qué sentido Hegel y Marx efectúan propuestas críticas distintas, aun cuando partan del mismo criterio lógico.

La pretensión de un lenguaje correcto - universal, ahistórico y acultural - hace del modelo formalista uno coherente, sistemático y demostrativo, basado en principios con los cuales es posible deducir todos los teoremas que el propio sistema genera. De esta manera, las reglas de inferencia, esto es, los criterios de las deducciones válidas, se fundan en los propios principios del modelo, lo que muestra su carácter autorreferencial —es decir, sin intervención alguna de elementos externos-.

Esta exclusión determina que el problema de la exactitud se limite al análisis de la estructura lingüística propia, lo que deja el asunto de la verdad reducido a "valor veritativo", esto es, a un dato que debe "ajustarse" a la gramática, si es verdadero; en caso contrario será falso. Así, la verdad depende de la validez, o dicho con otras palabras, el concepto antecede lógicamente a su contenido. Esta condición indica la prioridad de la razón — en tanto lenguaje "vacío" - sobre el contenido mismo o su identificación con una realidad en sí misma. En el primer caso, se trata de una relación dogmática y en el segundo, de una isomórfica.

El prejuicio característico de una relación dogmática entre un lenguaje formal y los contenidos - sensaciones, emociones y demás “materialidades"- que conforman la complejidad de la conciencia tiene idéntica estructura a la relación entre las formas “puras” del lenguaje y la realidad en sí misma: dar prioridad a la validez sobre la verdad identificando la primera con la segunda. Tenemos entonces una teoría de la verdad coherentista, cuyo criterio para distinguir entre lo falso y lo verdadero depende enteramente de la "correcta" formulación de las proposiciones y de la “adecuada” deducción en el orden argumentativo. 
La correcta formulación implica que las proposiciones no sean ambiguas, sino que su referencia sea un único objeto de pensamiento. En síntesis, que el término sea preciso, esto es, abstracto en su nivel referencial. De otro lado, la adecuada deducción toma los datos ajustados a la gramática, el valor veritativo de las premisas, en un estado inicial para luego hacer abstracción de esto en lo que respecta a la inferencia. La verdad de la conclusión del argumento "se desprende" del proceso gramatical más que del contenido. Para Lefebvre:

La gramática deja a un lado el sentido, el contenido, la verdad o la falsedad de la afirmación. Se ocupa únicamente de la manera de juntar las palabras; define ciertos caracteres generales, ciertas "clases" de palabras que hacen de ellas términos gramaticales y que deben regular su empleo: el sustantivo, el adjetivo, el verbo, el sujeto, el atributo, etc. (2006, p. 91)

Pensemos un caso que responda a la estructura simbólica, pero usando el lenguaje "ordinario": “Todos los hombres son mortales", que pudiera leerse como: "Si de un individuo puede decirse que es hombre, necesariamente debe decirse que es mortal”. Así, si de Juan puede decirse que es hombre, debemos decir necesariamente que es mortal. Para saber la verdad de tal deducción el antecedente de esta, la proposición "Juan es hombre", debe corroborarse. Ahora bien, para los lógicos formalistas si la verdad de "Juan es hombre" depende del orden epistemológico y metafísico, esta dependencia muestra las limitaciones del lenguaje. Se haría necesaria entonces una teoría de los conceptos distinta a la aristotélica. Para Aristóteles, como para otros estudiosos de la lógica "clásica", el concepto se asume como definición, lo cual es posible gracias a una ontología de carácter metafísico. Solo en cuanto el concepto define lo que es el objeto en esencia - esto es, solo en cuanto lo descubre instancia de un universalestamos ante la validez del conocimiento. Aquí el isomorfismo es entre la precisión de la palabra-definición y la realidad en sí, que no se construye de acuerdo a los sentidos, sino a una metafísica, a una cosmovisión:

Aristóteles ha buscado las condiciones de una lengua universal, las reglas de un empleo necesario de los términos creados por la práctica social, por el lenguaje corriente. [...] el gramático jamás hace otra cosa que codificar el uso práctico de una lengua determinada, y las formas gramaticales no pueden jamás separarse del uso; desde el momento en que se quiere tomarlas aisladamente, se cae en el formalismo. [...] La relación del pensamiento y el lenguaje 
- que se estudia tanto en psicología como en lógica- no es una relación simple. El acuerdo entre lenguaje y pensamiento se obtiene mediante una lucha, a través de un conflicto, resolviendo una contradicción incesantemente renaciente. (Lefebvre, 2006, pp. 91-93)

La crítica a la lógica aristotélica por la vía de radicalizar la formalización no logra superar, sin embargo, a la metafísica, sino que se transforma en psicologismo. Con la obra cartesiana se instaura un paradigma de pensamiento centrado en el ego. El isomorfismo se mantiene bajo otro ropaje: ya no entre la esencia de las cosas captada por el entendimiento y un lenguaje adecuado, sino entre una hipotética sustancia pensante y la realidad en sí. El concepto puro se identifica con la realidad en sí porque, tanto el pensar puro como lo que es en sí tienen forma geométrica - la legitimidad de tal isomorfismo está en asumir verdad como certeza-. Para los cartesianos la verdad se deduce de conceptos innatos, de acuerdo a la tradicional creencia de ser imagen de Dios, pero formulada en términos de ideas que no pueden ponerse en duda, como el dudar mismo. Por su parte, los empiristas no parten de ideas innatas pues estas no existen. Y lo que llaman idea no se entiende como proposición abstracta, sino como percepción sensible. Desde esta perspectiva la lógica sería un constructo lingüístico verdadero unas veces por correspondencia con la materia - para Locke esta está conformada por una hipotética sustancia insensible- y otras por simple concatenación de formas abstractas - para un Hume que rechaza la certeza de un conocimiento sensible de la sustancia pensante o de la materia y que, sin embargo, sostiene la existencia de una naturaleza humana-.

A pesar de la ruptura con la tradición aristotélica, los filósofos de la certeza y los empiristas mantendrán un esencialismo que vendría a ser superado por Marx, mucho antes que por Nietzsche o Heidegger. La persistencia de la ontología se mantiene debido al carácter autorreferencial del formalismo, pero con el giro fenomenológico emprendido por Kant la lógica dialéctica en la versión marxiana es capaz de romper con esta tradición.

A pesar de la obra de Hegel, por un lado, y la de Marx, por el otro, la línea formalista triunfa debido al auge del desarrollo tecnológico en Europa y Estados Unidos, más el perfeccionamiento de herramientas discursivas y analíticas. Un caso especialmente importante, por ser fundacional de la nueva versión del positivismo mecanicista del siglo xviII en el xx, es la obra de Gottlob Frege. 
Con este autor comienza una revisión de la lógica clásica a partir del análisis proposicional - de las expresiones del tipo “Todo A es B”- que modificaría el aristotélico análisis de acuerdo a la predicabilidad de las sustancias. En su lugar, aparece un cálculo predicativo en términos de relaciones, funciones o tipos asociados al sujeto de una proposición como lo que se dice de él. Si la verdad de la proposición radicaba, según la lógica clásica, en el hecho de que efectivamente lo que se predicaba de $A$, es decir $B$, fuera una característica inherente a aquel, con Frege y sus discípulos la cuestión se plantearía de manera distinta. La modificación de la morfosintaxis, ya no según la predicabilidad, sino de acuerdo a la noción de pertenencia de un "individuo" a una clase o conjunto, exigiría una mayor precisión en la corrección del lenguaje.

La proposición “Todo $A$ es $B$ ” tendría que modificarse a “Todo individuo que cumpla la función $A$ cumple la función $B$ ". De esta manera, tanto $A$ como $B$ son predicaciones y se leen como clases o conjuntos de individuos: "Si un individuo pertenece a $A$, también pertenece a $B$ ”. Un ejemplo de esta analítica proposicional se expresa en la uniformidad de los objetos de pensamiento. Analicemos la proposición anterior apoyándonos en la simbología matemática:

$$
x(A x \rightarrow B x)
$$

Dice que si lo que ocupa el lugar de $x$ cumple la función $A$, entonces cumple también la función $B$. Lo que sea $x$ es indiferente en términos formales: se trata de una variable, un lugar vacío en una estructura gramatical que puede ser ocupado por argumentos correctos o incorrectos (reprentaciones de individuos que pueden o no cumplir la función asociada). Si reemplazamos esta variable por un argumento, se podría leer de la siguiente manera: $a(A a \rightarrow B a)$, donde $a$ es un individuo determinado (una instancia particular de $x$ ) que cumple (o no) la función $A$ y, por lo tanto, necesariamente también (o no), la función $B$. Hasta aquí no se puede saber la verdad de las proposiciones, pero sí la garantía de la verdad.

La verdad en la lógica simbólica es conocida como valor veritativo y significa que el contenido de las proposiciones se limita a dos posibilidades: que una proposición sea verdadera o falsa. Y se entiende por verdadero que sea el caso que efectivamente x cumple la función $A$, y por falso, que no sea ese el caso. Sin embargo, la traducción del lenguaje ordinario a uno simbólicamente restringido elimina la complejidad que el primero expresa. Si suponemos que $a$ en su materialidad es "Juan”, diríamos que 
en sí mismo, "Juan” es un nombre que se le asigna a un elemento y que este pertenece al conjunto "humanos".

Como tales, las expresiones "Juan" o $a$ son indicativos de cosas, pero no expresan la cosa misma. Esto solamente es posible en el orden de las proposiciones. Dicho de otra manera, "Juan" es una indicación, pero no una descripción, y lo que es susceptible de ser conocido son los hechos, no los objetos nombrados. Así, lo que nosotros llamamos objetos son en realidad hechos. Las descripciones contienen indicaciones - $\mathrm{O}$ nombres, como los llama Russell—, mediante las cuales es posible hablar, establecer la "verdad", pero que no "son" esta. Mientras que de la proposición "Juan es hombre" o " $a(A a \rightarrow B a)$ " puedo decir si es verdadera o falsa, de la partículas "Juan" o $a$ no. Esta uniformidad del objeto de pensamiento en la que se hace abstracción de los contenidos pretende sustraerse de la ontología, cuando realmente encubre otra más: la existencia de entidades eternas o universales que pueden ser descubiertas por los científicos. Un pitagorismo refinado.

Los lógicos positivistas pretendían eliminar la ambigüedad de la expresión es, al despojar al sujeto proposicional de descripciones abreviadas u ocultas. Como consecuencia de este análisis, el lenguaje científico se vería liberado de seudoproblemas y el saber filosófico se limitaría al análisis del lenguaje, no a la explicación del mundo, y mucho menos a transformarlo.

La obra de Wittgenstein es un ejemplo de desarrollo de esta iniciativa y, sin embargo, para nosotros es posible articularla con la de Marx. Más exactamente, algunos de los planteamientos wittgensteinianos son compatibles con la teoría de la ciencia en Marx ${ }^{3}$. El tema de la ciencia como lenguaje descriptivo es también compatible con Marx, en tanto se pueda reconciliar a Wittgenstein con la fenomenología, cuestión que no resulta disparatada si se tiene en cuenta la amplia correspondencia que sostuvieron Frege y Husserl, por ejemplo. Hasta qué punto pueda articularse dicha reconciliación sería tema de intenso debate.

3 La proposición tan famosa de su Tractatus, "De lo que no es posible hablar hay que callar", se comprende si se considera que, de acuerdo a la teoría pictórica, el propio lenguaje solamente puede ser descriptivo, lo que deja de lado las intenciones. Pero a lo largo de la obra se muestran precisamente las limitaciones del lenguaje, asi que una posible interpretación de la referida frase es que de lo más importante -la ética y la estética- la ciencia formalista no puede hablar. 
El tema del logicismo o la lógica formalista desbordaría los límites de este espacio si ahondáramos en los diferentes aspectos que resultan oscuros, pero podemos considerar suficiente lo dicho para nuestros propósitos: comprender las características de una acepción de la lógica con la que se vio enfrentado Hegel y del proyecto que para el siglo xx pretendió superar la lógica hegeliana. Y es que tal intento no se redujo únicamente al hegelianismo, sino a Marx también, contribuyendo a la tergiversación de su pensamiento por parte de los antimarxistas y de algunos que se decían marxistas. En efecto, la eliminación de la lógica dialéctica de la obra de Marx la redujo a simple seudociencia - según Popper-o "a simple concepción del mundo" —en palabras de Alfred Schmidt refiriéndose al marxismo soviético-. En esta tergiversación se inoculó una lógica formal que parecía invertir el orden de las cosas. Si para los idealistas se trataba de una concepción del mundo esencialmente espiritual, para los materialistas en cambio el mundo era esencialmente materia. Nada de esto hay en Marx, sin embargo, pues no se desprende de su obra la idea de una sustancia material "pura”, así como en Hegel no se trata de un espíritu esencial en sí mismo. Y esto en razón a la lógica dialéctica. Si se cree que en Hegel o Marx hay una suerte de esencias independientes del mundo humano, es que en realidad se opera con una lógica formalista, positivista.

\section{La lógica dialéctica}

Ante todo ha de precisarse que la lógica formal responde a un momento del pensamiento y no al pensamiento mismo. Este es movimiento que, en contraste con el reduccionismo formalista, no se encuentra en estado de reposo absoluto, como en la tesis pitagórica. La formalización es el momento en el que el proceso del pensamiento se abstrae de sus contenidos para elevarse en proposición pura, vacía. Pero es tan solo un momento del proceso, no su culminación. Ya Hegel en su Fenomenología del espíritu plantea el problema de la formulación lógica de la verdad. La crítica al principio formalista de Aristóteles, el principio de identidad, compromete la columna vertebral de la lógica formal, pero también del estructuralismo pues al introducir en la proposición $A=A$ la duda sobre la identidad, necesariamente habrá de recurrir a elementos extraños a la proposición. Heredero de la visión intuicionista de Kant respecto de las matemáticas, Hegel considera que la verdad de la proposición $A=A$ se debe al movimiento del sujeto ${ }^{4}$. Al respecto dice:

4 Este concepto es central en la historia de la filosofía porque fue asumido principalmente como substancia, de latín subjectum, lo que subyace, lo fundamental, y no debe confundirse con entidad mental. 
Si el sujeto del saber se limita a hacer que dé vueltas en torno a lo dado una forma inmóvil, haciendo que el material se sumerja desde fuera de este elemento quieto, esto, ni más ni menos que cualesquiera ocurrencias arbitrarias en torno al contenido, no puede considerarse cumplimiento de lo que se había exigido, a saber: la riqueza que brota de sí misma y la diferencia de figuras que por sí misma se determina. Se trata más bien de un monótono formalismo, que si logra establecer diferencias en cuanto al material es, sencillamente, porque este estaba ya presto y era conocido. (Hegel, 2002, p. 14)

El sujeto pretendidamente absoluto, formal, en tanto se dirige a su objeto de pensamiento, también formal y abstraído de contenido, no puede obtener como conocimiento la forma "analítica" contenida en el concepto - lo que recuerda la exclusión que hace Kant de los juicios analíticos a priori del conjunto de las proposiciones científicas-. Y sí acaso el sujeto obtiene un saber por este método, es porque ya fenoménicamente en la forma se encontraba este contenido. Así, la formulación $A=A$ es verdadera absolutamente porque "antes" ha tomado su verdad del material en el que $A$ era distinto que A puesto que, en términos absolutos, de la unidad no se puede decir que sea algo. La identidad es un concepto sintético que no puede pensarse como un objeto, como "un algo". Y precisamente, solamente algo puede ser distinto de algo. Continúa Hegel:

El formalismo que la filosofía de los tiempos modernos denuncia y vitupera y que constantemente se engendra de nuevo en ella no desaparecerá de la ciencia, aunque se la conozca y se la sienta como insuficiente, hasta que el conocimiento de la realidad absoluta llegue a ser totalmente claro en su naturaleza. (2002, p. 15)

Esta temporal insuficiencia del concepto señala la limitación de la subjetividad moderna, centrada enteramente en un subjetivismo abstracto. La ciencia para Hegel se comprende más como un proyecto histórico que como un hecho. Y esta sería otra de las herencias que tomaría Marx. Siguiendo al maestro, en Marx el pensamiento responde a la praxis social. Pero leamos un poco más a Hegel para irnos acercando a esta idea de la lógica dialéctica y su influencia en Marx:

La sustancia viva es, además, el ser que es en verdad sujeto o, lo que tanto vale, que es en verdad real, pero solo en cuanto es el movimiento de ponerse a sí 
misma o la mediación de su devenir otro consigo misma. Es, en cuanto sujeto, la pura y simple negatividad y es, cabalmente por ello, el desdoblamiento de lo simple o la duplicación que contrapone, que es de nuevo la negación de la indiferente diversidad y de su contraposición: lo verdadero es solamente esta igualdad que se restaura o la reflexión en el ser otro en sí mismo, y no una unidad originaria en cuanto tal o una unidad inmediata en cuanto tal. Es el devenir de sí mismo, el círculo que presupone y tiene por comienzo su término como su fin y que solo es real por medio de su desarrollo y de su fin. (Hegel, 2002, p. 15)

Con estas breves palabras Hegel expone la crítica al logicismo incluso antes de su resurgimiento con el giro lingüístico, y esto en virtud de la inconsistencia del abstracto principio de identidad. Pues bien, el punto de partida en Hegel es la correspondencia entre la sustancia, lo que deviene, y el sujeto, la razón, también deviniendo. La realización en el devenir de lo que aún no es constituye la dialectización de la sustancia, no a partir de sí misma en su afirmación, sino de su negatividad, "la mediación de su devenir otro consigo misma”.

Esta inclusión de la negatividad de lo formulado en lo formulado implica una contradicción formal que obliga a la transformación cualitativa de lo formulado. Eso otro de la sustancia o la subjetividad es la todavía no realización, en el tiempo no psicológico sino histórico, de la substancia. Una vez irrumpe, la negatividad es negada en tanto negatividad y se afirma como novedad. Es en este momento cuando la identidad se hace posible y entonces $A=A$. Marcuse, acerca de la lógica en Hegel, señala en Razón y revolución que

la lógica de Hegel es una ontología en la medida en que trata de estas categorías (sustancia, afirmación, negación, limitación, cantidad, cualidad, unidad, pluralidad, etc.). Pero su lógica también trata de las formas del pensamiento, la noción, el juicio y el silogismo, y es, en ese sentido, "lógica formal”. [...] Según Hegel, la noción representa la verdadera forma del objeto, ya que la noción nos da la verdad acerca del proceso, que en el mundo objetivo es ciego y contingente. [...] Respecto a lo que una mesa es las cualidades particulares son al mismo tiempo, según Hegel, la "negación" de la mesa como tal. Las proposiciones con las que se predican las cualidades de la mesa indican este hecho. Tienen la estructura lógica formal A es B (es decir no A). "La mesa es marrón” expresa también que la mesa es otra cosa que ella misma. (Marcuse, 1994, pp. 67-69) 
La formalización de lo que se presenta ante el sujeto - para sí- es la negación de todo lo que es para sí. Por esta razón, la idea es opuesta a la manifestación fenoménica de lo sensible, y tiene que serlo si quiere establecerse como válida para todo fenómeno que corresponda al concepto. En efecto, la mesa en cuanto mesa-en-sí no puede ser marrón, ni alta, ni cómoda, ni de hierro o de plástico. En tanto objeto - entidad de pensamiento- la mesa es un concepto vacío.

La lógica formalista no comprende esta mediación a partir de la sensibilidad del sujeto en el tiempo y el espacio, sino que supone la existencia de entidades en sí mismas, como las categorías lógicas o los números. Hegel coincide con Parménides en que lo real es racional, pero con una variante: lo racional es real siempre y cuando deba ser real. En lugar del prejuicio isomórfico, la dialéctica hegeliana incorpora un pre-juicio deontológico. La historia es la realización de la Idea, en tanto voluntad de un sujeto que en su movimiento in-forma la substancia. Esta in-formación de la substancia que aún no es sujeto constituye todo el devenir de la Razón. Una relación de poder como dominio se instaura en el proceso del conocimiento. Así, el saber no consiste en descubrir la realidad, sino en racionalizar la naturaleza como proyecto ético histórico. Valga recordar que este sujeto no es el trascendental kantiano (el entendimiento), sino el sujeto histórico (racional). Con lo que se quiere decir que la ciencia es una conquista realizada por el hombre genérico, no por aquel atrapado en la inmediatez del presente.

El proceso epistemológico, en consecuencia, comienza con la materialidad en tanto negatividad, y el espíritu activo subsume esta otredad bajo el pensamiento abstracto transformándolo. La subsunción, que para Hegel se puede comprender como aufhe$b e n^{5}$, no es precisamente negación, sino la transformación de lo dado inmediatamente para ser abstraído en la subjetividad idealizada. Esa idea es sumamente importante en lo tocante a la epistemología marxiana, pero en su caso desde una subjetividad corpórea y comunitaria. Para Marx, según la interpretación de Dussel, el punto de partida de la abstracción, momento formal de la producción categorial,

5 De acuerdo con las diferentes acepciones en alemán de esta palabra la traducción no es simple porque tenemos que aufheben puede entenderse, no solo como "superar", siguiendo la traducción de Wenceslao Roces, sino también como "conservar", "anular", "terminar", "abolir", "resolver", "equilibrar". De manera que, para captar de mejor forma esta riqueza semántica cabria decir que la aufheben, de acuerdo a Dussel, se puede entender como subsumir, tal y como aparece, entre otros documentos, en los Grundrisse de Marx (como subsuntion). 
es lo "real y lo concreto (Realen und Konkreten)", lo supuesto en toda investigación. De ese concreto real (el sistema colonial latinoamericano, por ejemplo) tengo una "representación plena (volle Vorstellung)" o, de otra manera, "una representación caótica", inicialmente confusa, que, de todas maneras se sitúa ya en el "mundo conceptuado" (begriffne Welt). Para Marx, lo conocido (lo que está "en la cabeza [im Kopfe]") no puede confundirse con lo real, que guarda siempre una exterioridad de todo posible conocer, contradiciendo la posición fundamental de Hegel, ya que "Hegel cayó en la ilusión de concebir lo real como resultado del pensar”. (Dussel, 1985, p. 49)

En Marx hay también una oposición a la lógica formalista, sin suprimir el momento formal del proceso de pensamiento. Así, partir de lo real y concreto - que significa todo un complejo social, cultural, económico y político- es concebir lo real. Pero de esto no se ha establecido una representación plena, sino apenas una mirada superficial, aún no comprensible en su totalidad pues se muestra confusa o caótica. Tal representación plena se debe a un mundo conceptuado, y por lo tanto, siempre limitado, incompleto. Por esta razón, la idea, el concepto, no puede confundirse con lo real -tesis isomórfica del formalismo lógico-. Por eso Marx considera que Hegel cae en la ilusión de confundir lo real como producto del pensar. Dicho de otro modo, aun cuando Hegel adopta la lógica dialéctica, no es suficientemente consecuente con ella pues al priorizar la idea sobre la materia continúa en la línea que criticaba.

Con este giro se plantea una epistemología materialista, que no por eso se opone a la religión. Es decir, como la postura materialista marxiana no es una ontología — no postula un sustrato material independiente de las comunidades humanas-, no niega las estructuras simbólicas de las comunidades. Al contrario, el materialismo de Marx se inscribe más allá de una cosmovisión materialista como la que pensaban Demócrito o Epicuro. Por material ha de entenderse lo que es para sí en sentido fenomenológico, antes de su formalización —esto es, los contenidos de los juicios-, pero superando el idealismo en tanto supone un sujeto suprahistórico como el que postula Kant o el que propone Hegel, dada su identificación de sustancia y sujeto en devenir. Lo que determina los contenidos — la "negatividad" - en Marx es la praxis social antes que individual, fruto del trabajo social.

De manera que la filosofía de Marx procede fenomenológicamente con mayor profundidad que las de Kant, Hegel y los fenomenólogos posteriores a Marx. En la idea de 
mundo de la vida de Husserl, por ejemplo, la conciencia mantiene un carácter solipsista que omite la condición social de la conciencia humana. Por eso el "otro" aparece como un extraño absoluto. La problematicidad de esta propuesta excede los límites de la temática presente, así que se deja planteada la discusión. Por el momento veamos de qué manera la crítica de la religión no supone su negación, sino precisamente la posibilidad de su realización en el mundo concreto.

\section{La crítica de la religión como superación dialéctica del orden de un mundo. Feuerbach, necesario mas no suficiente}

La argumentación sobre la concepción de naturaleza en Marx implica retomar la crítica a la fijación del pensamiento en la formalización, que puede indicarse ya como fetichización del pensamiento, su relación con el "giro" filosófico hegeliano y la superación de este. De ahí la relevancia de la postura feuerbachiana y sus limitaciones, según Marx.

La reacción a la filosofía de Hegel, importante en lo que concierne a Marx, parte de la reacción de Feuerbach contra la teología, una crítica del cristianismo. Sin embargo, tal crítica no logra superar el presupuesto fundamental de todo idealismo: la preexistencia de un sujeto abstraído de las condiciones materiales. Esto es, persiste la ontología de una subjetividad no corpórea, y por lo tanto, menesterosa. Por esta razón, aun cuando Feuerbach aparezca como crítico del sistema hegeliano en nombre del materialismo, sigue siendo idealista porque no lograr "invertir" el método dialéctico en términos materialistas. Desde las famosas tesis sobre Feuerbach ya Marx no solamente esboza la crítica al materialismo acrítico de su mentor, sino también las bases del suyo propio. Dice Marx:

El defecto fundamental de todo el materialismo anterior -incluido el de Feuerbach - es que solo concibe las cosas, la realidad, la sensorialidad, bajo la forma de objeto o de contemplación, pero no como actividad sensorial humana, no como práctica, no de un modo subjetivo. De aquí que el lado activo fuese desarrollado por el idealismo, por oposición al materialismo, pero sólo de un modo abstracto, ya que el idealismo, naturalmente, no conoce la actividad real, sensorial, como tal. Feuerbach quiere objetos sensoriales, realmente distintos 
de los objetos conceptuales, pero tampoco él concibe la propia actividad humana como una actividad objetiva. Por eso, en La esencia del cristianismo solo considera la actitud teórica como la auténticamente humana, mientras que concibe y fija la práctica solamente en su forma suciamente judaica de manifestarse. Por tanto, no comprende la importancia de la acción "revolucionaria", “práctico-crítica”. (Marx y Engels, 1974, p. 7)

El materialismo vulgar o acrítico, como el de Feuerbach, mantiene una ontología del sujeto al imaginárselo como una sustancia abstraída de los procesos de producción social. Aun cuando esta antropología supone la corporeidad, la conciencia se mantiene en un topos inmaterial, bajo la tradicional distinción entre mente y cuerpo, y en una relación de dominio en la que necesariamente impera la conciencia sobre los contenidos. El sujeto es esencialmente "actitud teórica", sin poder comprender que tal actitud solo es posible en tanto actividad humana, es decir, en tanto la comunidad humana está articulada por el trabajo social y de acuerdo a los modos de producción que este genera. Ese entramado asimismo hace posible la conciencia individual. En la tesis 3 Marx añade:

La teoría materialista de que los hombres son producto de las circunstancias y de la educación, y de que, por tanto, los hombres modificados son productos de circunstancias y de una educación modificada, olvida que son los hombres, precisamente, los que hacen que cambien las circunstancias y que el propio educador necesita ser educado. (Marx y Engels, 1974, p. 8)

Con lo anterior se muestra no solo la imposibilidad del determinismo económico en el pensamiento de Marx, sino la negación de una ontología de corte materialista. Si se ve con cuidado, y en comparación con la tesis 1, se deduce que el trabajo social — esto es, los modos de producción de la vida comunitaria- incluye la invención no solo de la tecnología, el comercio o la industria, sino especialmente de una específica estructura mental correspondiente a "circunstancias" históricas, tecnológicas y educativas, que por ser circunstanciales pueden ser modificadas por los hombres. En otros términos, la invención de las circunstancias materiales, tanto las económicas como las simbólicas, se basa en el poder de transformación de la naturaleza por parte del trabajo social humano. Pero debe quedar claro que la modificación de la naturaleza nunca se presenta como es en sí - principio de la lógica dialéctica - sino para sí —criterio fenomenológico-. Así, los modos de producción de la vida implican una modificación 
de la materia, que se presenta en forma humanizada, incluida la corporalidad misma. Fenomenológica y dialécticamente procede el "logos" de Marx, adelantándose en esto a un Nietzsche que entre otras desconoce los modos de producción como determinantes de la voluntad de poder, de manera que se cierra sobre una única forma de concebir el poder: como dominio. Al contrario, con Marx la voluntad de poder es ante todo social, comunitaria. Por eso en la tesis 1 indica: "Feuerbach quiere objetos sensoriales, realmente distintos de los objetos conceptuales; pero tampoco él concibe la propia actividad humana como una actividad objetiva".

Si la actividad humana puede concebirse objetivamente, significa que puede medirse - es decir, basarse en leyes históricas, no naturales- lo que los seres humanos hacen. De nuevo se introduce otra distinción con la "ciencia" del formalismo lógico, y es esta: en el marco de la lógica dialéctica la tesis isomórfica no es posible. Con esto se quiere decir que el lenguaje formal no es reflejo de la realidad. Así, la ley, natural o social, responde a condiciones históricas, sociales. En La ideología alemana Marx afirma:

Solo conocemos una única ciencia, la ciencia de la historia. La historia solo puede ser considerada desde dos aspectos, dividiéndola en historia de la naturaleza e historia de la humanidad. Sin embargo, no hay que dividir estos dos aspectos; mientras existan hombres, la historia de la naturaleza y la historia de los hombres se condicionan recíprocamente. (Schmidt, 1983, p. 45)

Las leyes de la naturaleza se construyen en el trasegar histórico, no se descubren, gracias al desarrollo de la industria y el comercio. De acuerdo al desarrollo de la historia humana se desarrolla la ciencia, tan histórica como humana. Por esta razón en la tesis 3 la transformación de los seres humanos es una práctica humana al tiempo que científica. Solo la división social del trabajo ha hecho creer que la producción intelectual es independiente de la producción de los medios de subsistencia. Pero en el sentido en que se entiende la ciencia aquí — como constructo materialista - se trata más bien de un único saber, lo que deja sin fundamento la típica pero errónea división entre "infraestructura” y "superestructura" atribuida a Marx.

En efecto, no hay un determinismo económico cuya transformación implicaría necesariamente la revolución de las instituciones humanas - construcciones simbólicas-. Muy al contrario, si se concibe la "ley natural" tan solo como el nivel formal - es decir, como abstracción- de los procesos del desarrollo de los modos de producción, se 
obtienen los objetos de la ciencia, los cuales están sujetos, como las relaciones sociales, a transformaciones revolucionarias ${ }^{6}$.

Resulta interesante lo referido por Marx en relación con la ciencia y el desarrollo de las fuerzas productivas. En La ideología alemana, explica:

La producción de la vida, tanto la propia en el trabajo, como la ajena en la procreación, se manifiesta inmediatamente como una doble relación —-de una parte, como una relación natural, y de otra como una relación social—; social, en el sentido en que por ella se entiende la cooperación de diversos individuos, cualesquiera que sean sus condiciones, de cualquier modo, de cualquier fin. [...] El "espíritu" nace ya tarado con la maldición de estar "preñado" de materia, que aquí se manifiesta bajo la forma de capas de aire en movimiento, de sonidos, en una palabra, bajo la forma del lenguaje. El lenguaje es tan viejo como la consciencia: el lenguaje es la consciencia práctica, la conciencia real, que existe también para los otros hombres y que, por tanto, comienza a existir también para mí mismo. (Marx, 1974, pp. 28-29)

De un lado, la idea de producción de la vida nos hace pensar en un vitalismo no abstracto. La fuente de todo valor es la vida misma sin tener ella valor en tanto tal. En este sentido, toda producción económica está originariamente condicionada y orientada hacia la conservación de la vida. También expresa esta cita que tales procesos de producción pueden verse como naturales al tiempo que sociales, lo que hace alusión al carácter social de lo humano. Pero lo que resulta más interesante para los propósitos de este trabajo es la consideración materialista de la consciencia. El lenguaje es la propia expresión de las necesidades prácticas de establecer relaciones humanas no satisfechas por la simple "animalidad", y por lo tanto, esta consciencia práctica es fruto de la respuesta social al desafío de una vida hostil. Solo la organización social de las fuerzas de trabajo, que implica relaciones lingüísticas, pudo hacerle frente. Incluso la idea de que el concepto antecede al contenido responde a una construcción histórica. "La naturaleza es para Marx un momento de la praxis humana y al mismo tiempo la totalidad de lo que existe” (Schmidt, 1983, p. 23).

6 Piénsese, por ejemplo, en el desarrollo de la química, que tiene como antecedente a la alquimia, cuya "intención" humana consistía en el interés de transformar cualquier metal ordinario en oro, uno de los metales preciosos que fue acuñado como moneda en varias regiones de Oriente y entre los árabes musulmanes. 
Sintetizando, la diferencia entre Hegel y Marx no radica en que el primero sea idealista y el segundo, materialista. Se trata, en su lugar, de que Hegel al partir del concepto (del Ser) no es consecuente con la lógica dialéctica. Mientras Marx parte de la creación de un momento anterior al concepto y da mayor sentido al logos de la negatividad. En efecto, la idea en Hegel está "mágicamente" — es decir, ahistóricamente - supuesta e identifica sustancia con sujeto. Tal suposición no es gratuita pues parte de la tradición "moderna", formulada ideológicamente desde Descartes, que funda la certeza como axioma del conocimiento verdadero. Si bien Hegel critica este principio remontándose a la lógica dialéctica clásica, no logra ver que se mantiene el principio aristotélico en su "ontología" al identificar, tal como hacen los filósofos anteriores a él, sustancia con subjetividad.

Para Marx, por el contrario, no hay primacía ni del sujeto ni de la sustancia. La naturaleza no es un en sí, como tampoco lo es la consciencia. Lo que en cambio sí aparece como condición primera, mas no ontológica, es la corporeidad humana, que no es exclusivamente material ni es principalmente "espiritual". Lo que sea tal corporeidad está determinado no por una sustancia transhistórica - tesis historicista-, sino por la relación dialéctica entre las comunidades humanas en la naturaleza a través del trabajo social. Por eso debe aclararse que la idea de una dialéctica en la naturaleza es ajena a Marx. No existe tal dialectización de la naturaleza en sí misma, idea propiamente engelsiana y marxista-leninista. Como se ha intentado mostrar, la lógica es llevada a su plenitud cuando se yergue en sus propios pies, al decir del mismo Marx. La teoría marxiana es mucho más consecuente que otras pues evitar caer en la desacralización de la naturaleza, como sucede con los filósofos modernos, incluido Hegel. La desacralización de la naturaleza está sustentada en la voluntad de dominio, que muestra su mayor ferocidad después de 1492, en el momento en que Europa logra romper su condición periférica con respecto al centro cultural y económico del momento.

La sacralización de la naturaleza presente en la obra marxiana es expresión de la crítica de la religión. Esta crítica, como mencionamos con anterioridad, comienza filosóficamente con Feuerbach y su comprensión de la tradición cristiana. Pero pudiera darse un paso más si se considera el ambiente cultural en que se encuentra Marx. La cultura semita, presente en Europa desde los tiempos del Imperio romano, heredó por lo menos dos comunidades judías en los extremos de la pequeña Europa: los sefardíes y los askenazis. Estos últimos se establecieron en la actual Alemania, mientras los primeros lo hicieron en la península Ibérica. Marx lleva tras sí la tradición judía y es palpable 
la influencia de filósofos judíos como Spinoza, en cuya obra es posible encontrar una concepción sagrada de la naturaleza. Consideramos que en el pensador alemán hay también una sacralización de la naturaleza, pero en el sentido ya indicado.

\section{La religión, de ser liberadora, superará el fetichismo}

En sintonía con el pensamiento marxiano, es propio pensar en las "circunstancias" históricas de la producción teórica. La crítica a la religión realizada por Marx se define a partir del concepto de fetiche, entendiendo por tal la atribución de características absolutas, divinas o sagradas a objetos que no las tienen. De esta forma, en la teología de Hegel está fetichizada la sustancia, aun cuando se haya intentado separarla de su ropaje trascendental. En este caso, el historicismo resulta ser una fetichización de la historia, al intentar dotarla de sentido. Según Alfred Schmidt:

Para Marx, el mundo en su conjunto no está sometido a ninguna idea unitaria que le confiera sentido. Para él solo vale lo que Hegel llama "el punto de vista finito-teleológico": fines finitos de hombres finitos condicionados en el tiempo y el espacio, frente a dominios delimitados del mundo natural y social. (Schmidt, 1983, p. 30)

La confusión de ese "punto finito de hombres finitos" con la esencia de lo real es justamente la fetichización que, en términos de la teología judía, consistiría en la representación antropomórfica o zoomórfica de lo divino. En contraste, la teología cristiana de los filósofos sí tiene representación de lo divino en la forma de sujeto volente que o domina la naturaleza en tanto se le opone en su ser, como ya vimos, o se identifica con lo real en sí, más allá de lo dado.

Sírvanos contrastar ese modelo teológico "moderno" de la teología filosófica cristiana con una visión modernizada de origen semita radicalmente opuesta. La filosofía de Spinoza es una ontología en la que la naturaleza se identifica con la sustancia misma, pero sin contradicciones. La manera como este autor presenta su obra cumple con toda la apariencia del formalismo lógico cartesiano. Sin embargo su metafísica responde a un horizonte religioso diferente al de Descartes o Hegel. Tiene como elementos constitutivos la dignificación de la corporeidad y la no representación de lo sagrado bajo ningún concepto ontológico. Así, la única sustancia y sujeto posible, y por tanto necesario, es Dios. Como tal, este es tanto idea como cosa extensa, 
es infinito. La "armonía” de Dios —en tanto causa (naturante) y como naturaleza (naturata) - cumple con un único orden posible, y por eso mismo necesario. La dualidad cartesiana está ausente en la teología de Spinoza pues el hombre no es una sustancia, como tampoco su cuerpo. Ambos son solo modos de ser de Dios. Lo que se entiende como sustancia en Descartes y los racionalistas, incluido $\mathrm{Hegel}^{7}$, es en Spinoza un atributo de Dios.

Al no existir oposición entre naturaleza e idea, la filosofía spinocista sería materialista, no porque en la materia permanezca el sentido de lo sagrado, sino por ser dicha filosofía una ontología. Sin el recurso a la metafísica de un ser causante, la ética pudiera acercarse aún más a Marx. Bajo el principio de connatus Spinoza argumenta en favor de una ética sostenida en la tesis de la preservación del hombre y de su no-dualidad mente-cuerpo. Dice Spinoza en su Ética:

Los individuos que componen el cuerpo humano y, por consecuencia, el cuerpo humano también, son afectados de muchas maneras por los cuerpos exteriores. [...] El cuerpo humano necesita para conservarse, de muchos otros cuerpos, que producen en él una especie de regeneración continúa. [...] Pero todo lo que sucede en el cuerpo humano, debe percibirlo el alma humana. [...] Según esto, se da necesariamente en Dios una idea de cada individuo que compone el cuerpo. (Spinoza, 1998, p. 47)

De acuerdo con estas proposiciones, expuestas según el orden geométrico que Euclides empleó para demostrar el teorema de Pitágoras, se deduce — aunque en realidad se muestra - el dogma de la unidad divina, compartido por las tres religiones del Libro. Añade el filósofo de Ámsterdam una idea que nos interesa en relación con Marx: la sacralización de la naturaleza. Si para el pensamiento moderno el hombre se ha erigido como amo y señor de esta, en el sentido espinosista la naturaleza deja de ser solamente una creatura distante de su creador. Esta tesis le valió la excomunión de la comunidad judía.

Si bien el hombre es tan solo una forma finita, participa de la naturaleza divina, que es infinita, por ser un modo de ser de la divinidad. Así, la postura spinosista dota de

7 Aun cuando se ha dicho que en Hegel sustancia y sujeto se identifican, sigue presente la preeminencia del segundo sobre la primera, por lo menos en cuanto que esta es la "negación", el "todavía no ser" del sujeto. 
sacralidad al cuerpo humano en términos del amor, de la armonía con el Ser. El hombre entra en armonía con Dios en tanto comprende la naturaleza.

Y con todo, todavía faltaría algo fundamental, la historicidad. El error de Spinoza es concebir la naturaleza como en sí misma, no mediada por el hombre. Aquí se distancia Marx de su correligionario, aunque coincidan en no condenar la corporeidad. El monismo teológico de la cultura religiosa de Marx tiene una eticidad que dignifica la carne, en la que no se concibe la corporalidad como antítesis del espíritu. Su origen semita da cuenta de esta "honorabilidad" del cuerpo, que por cierto se manifiesta en el mito cristiano de la resurrección de la carne. La sangre y la corporalidad son valiosas en sí mismas, al punto de convertirse en fundamento de todo valor.

Ya sin sustancias trascendentes, ni idea ni materia en sí, la filosofía de Marx se comprende entonces como una ética cárnica. Pues toda la crítica y el ideal de superación del modo de vida capitalista, y en general de toda forma de organización de la vida no equitativa, parte de este criterio semita de la dignidad de la corporeidad. El problema de la eticidad del capitalismo consiste en su inmoralidad inherente.

La lógica del modo de producción capitalista procede apropiándose del excedente de fuerza de trabajo de quienes hacen posible - crean - lo que "el cuerpo necesita para autoconservarse". Esta apropiación queda oculta en la formulación de la "verdad" del capital, es decir, bajo el ropaje de la mercancía. De ahí la necesidad de una racionalidad que des-cubra lo que oculta la forma del capital. Tal racionalidad la ofrece la lógica dialéctica, que ya Hegel mostraba en su célebre dialéctica del amo y el esclavo.

Lo que ocultan las teorías que legitiman el modo de vida capitalista es la inmoralidad de la praxis de la sociedad capitalista puesto que bajo el concepto formal de ganancia permanece oculta una serie de acciones consistente en la sustracción del excedente de la fuerza de trabajo que el obrero vende al capitalista. En Trabajo asalariado y capital Marx explica cómo, tras la venta de la fuerza de trabajo - es decir, de ofrecer a cambio de dinero la inversión de energía corporal por un tiempo determinado-, un obrero crea valor de cambio en "una acumulación de trabajo ya existente", que no será consumido inmediatamente.

Esta creación no le pertenece, sin embargo, porque la ha vendido, ha recibido a cambio un pago, el salario. Pero si se analiza dialécticamente y con el criterio ético de la 
dignidad de la carne, se descubre que tal compra-venta es inmoral. Al preguntarse por el coste de producción de la mercancía que hace posible las demás mercancías - es decir, la fuerza de trabajo-, dice Marx:

El precio del trabajo se hallará determinado por el coste de producción, por el tiempo de trabajo necesario para producir esta mercancía que es la fuerza de trabajo. Ahora bien, ¿cuál es el coste de producción de la fuerza de trabajo? Es lo que cuesta sostener al obrero como tal y educarlo para este oficio. [...] El precio de su trabajo estará determinado por los medios de vida indispensables. (Marx, 1974, pp. 161-162)

El precio de la fuerza de trabajo se determina por el cálculo de la inversión de productos que la hacen posible, como el alimento, el vestido o la instrucción, en función del tiempo empleado en la producción de tan especial mercancía. Considerando el valor de la fuerza de trabajo, por cuanto esta es capaz de crear la realidad, el sistema salarial resulta un robo. El salario se expresa en términos de valor de cambio - en dinero o especie - de la fuerza de trabajo empleada, no de la totalidad de su valor, siendo el excedente de esa fuerza acumulada en el proceso productivo el origen de la ganancia. De esta manera, el plus-trabajo es el que genera plusvalía, siendo confundida esta ecuación des-proporcionada con la ganancia.

El problema no se limita a la menor percepción de dinero en el contrato, por ejemplo. Se extiende el robo a algo mucho más profundo y muchas veces “ocultado". La exclusión de los obreros de la distribución de la riqueza social consiste en que estos no puedan acceder a lo que la sociedad en su conjunto ha logrado. Así, ser rico no consiste en controlar los medios de producción, sino en poder consumir los bienes materiales producidos socialmente. Bienes materiales no son únicamente lo que vulgarmente llamamos "cosas sensibles", como carro, casa o joyas. Materiales también son el conocimiento, la cultura y los lazos afectivos puesto que son también producto del trabajo social. Se pudieran concluir diferentes proposiciones al respecto que reñirían con la versión vulgar del marxismo.

Una de ellas sería que la lucha de clases ha de entenderse más como una interpelación por el acceso a los bienes, y no como una simple mejora de los salarios, o que la riqueza no consistiría en la acumulación, sino en el mejor - no mayor - consumo de estos bienes. La mayoría de la población mundial, porque se trata de un sistema 
mundial de producción, se encuentra por fuera de la distribución de la riqueza, incluidos muchos que tienen bastante dinero, pero no cultura.

De ahí que el problema de la economía política no se restringe exclusivamente a la abstracta repartición del fetiche del dinero. Este no es riqueza ni conduce a ella. Confundir dinero con riqueza es igual que hacer una estatua para adorarla como si fuese un dios. Es un pecado de idolatría que todos los profetas judíos, Jesús y Mahoma condenaron. Asimismo, con Marx diríamos que la fetichización del dinero es un acto de idolatría nada inocente pues ante su altar (las industrias, las minas de Potosí o de Sierra Leona) se sacrifica lo más sagrado: la corporeidad de los obreros, esto es, la posibilidad de producir, reproducir y desarrollar la vida humana.

Por eso también se sacrifica ante este dios la vida de los que poseen los medios de producción, porque desperdician trabajo social acumulado en la industria y el comercio en el consumismo y el derroche. Podría objetarse que estos mismos, comprendidos abstractamente, puede que no sean responsables directos. Pero vistos dialécticamente son un sujeto social alienado, esto es, escindido de su propia producción. En efecto, aun cuando no son productores directos de capital, la apropiación de los bienes producidos por la cultura les resulta extraña por ser abstracta.

El descubrimiento de esta exclusión humana, producto de su propia fuerza productiva, como inherente al modo de producción de vida capitalista (Dussel), es científico. Se basa en la aplicación del materialismo histórico, que no comprende la praxis como actividad de hombres abstraídos de las relaciones sociales - propia de las ciencias sociales acríticas-, y por ende, tampoco ignora las condiciones materiales de tal praxis - sesgo en el que caen muchos enfoques de las ciencias duras-.

El ecocidio, el asesinato de la "naturaleza" - que en términos de lo expuesto llamaríamos materialidad primaria humanizada ${ }^{8}$ - está siendo cometido bajo la "lógica" de la explotación obsesiva del capital. La sobreproducción y el consecuente despilfarro de los recursos naturales - y por ende, de vidas humanas- es en su conjunto un complejo irracional, no científico, porque atenta contra la fuente de la riqueza: la posibilidad de la vida humana y no humana. La epistemología es, dialéctica e históricamente hablando, una ética.

8 La posibilidad de concebir siquiera una naturaleza en si misma no tiene sentido en los términos que estamos trabajando. 


\section{Marx a pesar de Marx. Lectura poseurocéntrica de la obra marxiana. Superación de eurocentrismo de Marx en su propia lógica}

La crítica de Marx está vigente no solo porque metodológicamente es compleja — contraria a la chata visión de "críticos" como Karl Popper" —, sino sobre todo porque resulta un instrumento de análisis para muchos aspectos de la vida humana. El pensamiento de Marx es humanista y ético, antes que una abstracta teoría de la academia, aun cuando se sirva de sus herramientas. La crítica a la economía política, categorial y abstracta, podríamos concebirla como el "nivel formal” de su pensamiento (Dussel). Pero su contenido material concreto se basa especialmente en la historia de Europa, o más precisamente en una historiografía eurocéntrica que le impidió comprender, por ejemplo, el problema del colonialismo en la India o el fenómeno de las independencias en América Latina. Sin embargo, tal sesgo no impide "actualizar" a Marx, como de alguna manera hizo José Carlos Mariátegui. El punto de partida es, en concordancia con el método, una crítica al modelo eurocéntrico, y de nuevo, tomar los elementos críticos de la obra de Marx: la filosofía no ontológica de la naturaleza. Una vez establecidos esquemáticamente estos puntos, deberá indicarse en qué sentido es posible hacer una crítica de la razón eurocéntrica a partir de Marx.

En la misma obra de nuestro pensador se encuentran elementos para una crítica de la razón eurocéntrica. Ante el mito académico de la creación de ganancia los análisis de Marx son contundentes porque demuestran el origen del capital. La plusvalía, como ocultación-negación del obrero en la formalización de la economía burguesa, no aparece como categoría económica. La ganancia es pensada como mito o axioma evidente de una regulación de la naturaleza humana (Castro-Gómez, 2011, p. 45). Este descubrimiento se basa en los hechos históricos fundantes de la Modernidad: el descubrimiento del océano Atlántico como nueva ruta comercial, la expoliación de lo que hoy se conoce como América Latina bajo el sistema colonial español y el posterior saqueo de la fuerza de trabajo acumulada en África y Asia. Estos trascendentales hechos, sobre todo el primero por ser fundacional, aclaran el misterio de la hegemonía europea.

9 Gómez (1995) muestra la ignorancia de Popper sobre el materialismo histórico y sobre Marx mismo. 
El oro, entre otras formas dinerarias como la pimienta o la seda, se convirtió para el mundo del Mediterráneo en uno de los modos de comerciar con "Oriente" —que constituía el "centro" del sistema regional hegemónico antes de 1492 (Frank, 1985) - . Europa era pues una provincia, y por tanto, “periferia” del centro hegemónico controlado por los musulmanes - e indirectamente por los chinos-. De ahí el interés por apropiarse de rutas alternas ya descubiertas por los chinos por lo menos cien años antes (Menzies, 2015).

Pero con la superación de la situación periférica de Europa, producto de la extracción de oro y plata en varias regiones de América, especialmente en las minas de Potosí, pudieron echarse a andar procesos industriales y comerciales en la naciente Europa. Marx menciona este hecho en varias obras suyas - el Manifiesto, El capital (cap. XxIv) o el ya citado Trabajo asalariado y capital_- Dice Marx:

En el siglo XVI, a consecuencia del descubrimiento en América de minas más ricas y más fáciles de explotar, aumentó el volumen de oro y plata que circulaba en Europa. El valor del oro y la plata bajó, por tanto, en relación con otras mercancías. Los obreros seguían cobrando por su fuerza de trabajo la misma cantidad de plata acuñada. El precio en dinero de su trabajo seguía siendo el mismo, y sin embargo, su salario había disminuido, pues a cambio de esta cantidad de plata obtenían ahora una cantidad menor de otras mercancías. Fue esta una de las circunstancias que fomentaron el incremento del capital y el auge de la burguesía en el siglo xvi. (Marx, 1974, p. 169)

La obtención de metales preciosos con mano de obra esclava constituía una plusvalía del $100 \%$ al no descontar por la ganancia ningún tipo de salario, lo que diferencia profundamente al obrero del pobre. El primero percibe por lo menos un pago por la venta de su fuerza de trabajo, mientras que el segundo se encuentra totalmente a la intemperie, ni siquiera vende tal fuerza. Pero el pobre es condición necesaria para la conformación del obrero en razón a su condición.

En efecto, el pobre es categorialmente hablando anterior al obrero. Solamente quien se encuentra a la intemperie, es decir, expuesto a la muerte porque no tiene más que su cuerpo o sus hijos, ha de vender su corporeidad para salvarse. En ese sentido, es un pobre y un "ser para la muerte” que será redimido por el trabajo. En tanto obrero es aún un ser humano incompleto, un ser por realizarse, por ser ahora un productor 
al que su trabajo, dado el sistema salarial, en lugar de hacerlo más humano, lo limita a no acceder al consumo.

Esta contradicción entre lo que ha producido y lo que consume la mayoría de la población mundial se debe no a una esencia perversa, angustiada o malvada, sino a la creación de condiciones favorables a la exclusión y la explotación. La exclusión del hombre del reino de la libertad que él mismo ha creado es histórica, tiene fecha de nacimiento y fenecerá cuando los propios hombres decidan su propia historia. La acumulación originaria - que situó, de manera extraordinaria, en el centro a los europeos y posteriormente a Estados Unidos - tiene apenas algo más de quinientos años y su colapso es inminente, particularmente por una razón: la destrucción del nicho humano. En consecuencia, tal destrucción no se deberá a la "malignidad" intrínseca de la humanidad, y su redención tampoco responderá a una hipotética "bondad" inherente. Si no se detiene la irracionalidad del capitalismo, es seguro que la humanidad desaparece.

Aquí se pueden encontrar, si se ahonda en la historia de América, conceptos "extraños" para la tradicional historiografía eurocéntrica que, no obstante, pudieran deducirse de la obra marxiana. Las instituciones económicas, políticas y culturales basadas en la estrecha visión hegeliana del "progreso" civilizatorio no alcanzan para explicar la economía colonial moderna. En efecto, la "realidad" de América Latina no puede mirarse con el esquema eurocéntrico de la historia. La mita y la encomienda, por ejemplo, no son propias del sistema feudal, son capitalistas.

Gracias a estas estructuras fue posible la acumulación originaria, pero no como antítesis - momento a superar-, sino como negatividad propia -oculta-del modo capitalista. Una negatividad todavía más profunda que la planteada en el esquema del capitalismo industrial eurocentrado. Esas dos instituciones económico-políticas fueron inherentes al modo de producción capitalista porque se basaron en la expoliación de la fuerza de trabajo no asalariado, condición necesaria para la aparición histórica del capitalismo industrial europeo. La teoría de la dependencia, desarrollada por Frank y otros, es compatible con Marx (Dussel) precisamente porque tiene como marco de referencia crítico la acumulación originaria.

La materialidad mundial requiere, con la des-eurocentralización, una ampliación de la crítica, y se torna de mayor criticidad que el marxismo estándar. El empobrecimiento 
de centenares de pueblos originarios de América, África, Asia y la propia Europa no se debe a que estos no hayan alcanzado la modernidad o no se hayan civilizado. El empobrecimiento se debe al epistemidicio llevado a cabo por esa misma modrnidad. Vista desde la perspectiva del giro decolonial la filosofía de Marx sirve para plantear científicamente una superación ética y humanística radical. Si la alienación humana en el capitalismo inglés queda negada en la forma de las mercancías - excluyendo a los obreros de la riqueza social-, mucho más empobrecida se verá la población. Y no solo la inglesa, sino la de las colonias, si se considera la desaparición de milenarios e innumerables modos de producción social, económica y política tras el proceso de conquista y colonización.

\section{Palabras finales}

Leer a Marx, y por extensión a cualquier filósofo serio, exige considerarlo de acuerdo a las limitaciones históricas y culturales en las que vivió y desarrolló su pensamiento, al tiempo que actualizarlo conforme a los problemas que nos aquejan. Solo así se puede leer críticamente, sin la pretensión fútil de creer que se lo comprende en su totalidad y mucho menos, que lo expresado por él es palabra sagrada. La analítica de su obra, las lecturas en contexto y la crítica de sus falencias hacen de la obra de Marx un instrumento importante para pensar el mundo de hoy. Este trabajo ofrece una lectura de un Marx científico, desde la perspectiva de la lógica, la tradición semita y el eurocentrismo. Temas apenas trazados que, por su densidad, necesitan un espacio de desarrollo mayor.

\section{Referencias}

Bartra, R. (2014). Antropología del cerebro. México: FCE.

Castro-Gómez, S. (2011). Filosofía, ilustración y colonialismo. En E. Dussel, E. Mendieta y C. Bohórquez, Pensamiento filosófico latinoamericano, del caribe y "Latino" (1300-2000) (pp. 130-145). México: Siglo XXI.

Dussel, E. (1985). La producción téorica de Marx. México: Siglo XxI.

Frank, A. (1985). La acumulación mundial, 1492-1789. México: Siglo xxi.

Gómez, R. (1995). Neoliberalismo y pseudociencia. Buenos Aires: Lugar S. A. 
Hegel, G. (2002). Fenonomenología del espíritu. México: FCE.

Lefebvre, H. (2006). Lógica formal, lógica dialéctica. México: Siglo xxi.

Marcuse, H. (1994). Razón y revolución. Madrid: Altaya.

Marx, K. y Engels, F. (1974). Obras escogidas. Volumen I. Moscú: Progreso.

Menzies, G. (2015). 1421. El año en que la China descubrió el mundo. Barcelona: Penguin Random House.

Schmidt, A. (1983). El concepto de naturaleza en Marx. México: Siglo xxi.

Spinoza, B. (1998). Tratado teológico-político / Ética. México: Porrúa. 